\title{
Agile Transformation as an adaptive system
}

\author{
Luc Taesch 1, Christophe Rochefolle 2 , Miloud Touirat, Denis Mortreux , Stephan Boulinguez ${ }^{3}$, \\ Daniel Polombo ${ }^{4}$, Patrick Manoukian ${ }^{5}$
}

1 AFSCET French Association of Systemics and Cybernetics, Paris, France, Europe

C2C, Coach of Coachs, Peer Development group, Paris

Engie.com , 102 Avenue Aristide Briand, 92220 Bagneux, France

2 eVoyageurs.sncf 124 W 133rd Street Unit \#2, New York 10030, NY

3 eVoyageurs.sncf 91, rue nationale, 59000 Lille, France

4 Cloud@p , 4 rue Pierre de Ronsard, 62119 Dourges , France

5123 Rue de la Reine Blanche Bat C2, 78955 Carrières-sous-Poissy, France

Correspondence: luc.taesch@gmail.com ;

\begin{abstract}
Most mature companies have started some kind of "transformation", either digital, or agile transformations, to cope with changes in the environment, yet most fail, ending up delivering nothing or just one more reorganization. We postulate that considering the Organization as a self-aware Complex Adaptative System (CAS) is paramount, as the common conception (Industrial: mechanistic and predictive) results in bringing the systems in a frozen or defensive mode. Stimulating the system enables us to use its adaptative power to develop new capabilities, and all layers should be tackled simultaneously, to prevent the system from collapsing back into its original state. To ensure this, it is necessary to create a seed per level, and a mechanism to propagate the transformation, with a focus on development instead of growth, that is qualitative change rather than quantitative. A common vocabulary should also be provided, so conversations can occur at every level. Finally, changing mindsets is key, and both concepts and techniques should be provided as enablers to the adequate mindset level. We detail one such transformation that resulted in distributed leadership and more intrinsic motivation, providing both an account of the transformation itself and a model to read it.
\end{abstract}

Keywords: Complex Adaptative Systems (CAS), Complex Sociology, Socio Ecological Systems (SES), Constructivism, Spiral Dynamics, Systemic Governance, Polycentric Institution Governance, Innovation Facilitation, Transformation, Agile.

\section{Introduction}

Most company are currently embroiled in a digital transformation, because of Internet, of competition; or because of Covid-19. For instance, having a digital presence used to be "cool", then "must have", and now it's become a life-and-death issue ${ }^{1}$.

Hence, most mature companies have started some kind of "transformation", either digital or agile transformations, to cope with these changes in the environment.

The perfect example of a successful transformation is Netflix: before the transformation, Netflix was renting DVD, sending them by post. It went on to become the pioneer of Video On Demand (VOD), and its operations went from distributing parcels by post to a pure IT Business. Different model, with different people. Then Netflix started producing its own original films. A totally new business

${ }^{1}$ for those facing Amazon for instance. Amazon currently has about $44 \%$ of U.S. e-commerce market share, Walmart is a distant second at just $7 \%$. Wallmart was an undisputed market leader before Amazon 
again, artistic production. Nowadays, competitors from the Netflix rent-a-DVD era have disappeared, as nobody rents DVD anymore, and Netflix is the leader of a market it created.

"It is not necessary to change. Survival is not mandatory" - E. Demings.

But Netflix is an exception, as over $70 \%$ of the companies fail to transform [1]. This goes mostly undocumented, as no listed company will publicly admit to such failure, to avoid market reactions for instance. In some cases, this results in CEOs being removed from position - and still thanked for their services and achievements. Yet their replacement will often just launch a new transformation plan right off the bat. In many other cases, the net result is just another reorganization, with more energy spent on painting it off as an actual transformation than in actually improving the situation.

There was a time where reorganizations were the ultimate cure to any issues. But no amount of reorganization is going to help a company go digital, and the confusion between reorganization versus a transformation should be cleared. There are 3 levels of changes separating them, as we will see further in the ladder of change ${ }^{2}$, but even so-called change experts are mostly unaware of this confusion. Yet when not addressed, this usually means failing to transform, then potentially a global failure of the company, like Kodak [2][2] or Nokia [3] can attest.[3] IT companies (or IT departments) are under heavy pressure to adapt to this faster world and going "agile" is the latest fad in the IT transformation world. In short, agile is a move from a Pyramidal, Taylorian, command and control organization towards autonomous teams and a product driven organization. These ones mostly fails too [4] , despite a clearer path.

We posit that the problem relies on the viewpoint from which to consider an organization. The common viewpoint towards an organization is mechanistic and predictive, like a "factory" [5]. There is a series of objects (the assembly line), and you can change it, move them, reorganize them. Adjust the workflow, considering humans as simple resources that will adapt. This viewpoint faces the "resistance to change" issue (homeostasis) [6] [7][8]. Agile transformations have a more humanistic approach, and still fail at applying it to a large organization [9] [10].

We propose to consider organization as a Complex Adaptative System (CAS), and use its adaptative power to develop new capabilities, by stimulating it. The movement come then from inside, and not from "outside".

We detail one transformation using this approach, as an example. We detail the outcome, the techniques used to stimulate it on several levels simultaneously, and the two models: the viewpoint of an organization (as a CAS) and the diffusion model, the mechanism to propagate it through the organization.

Who can benefit from this ? We met a few CEOs and C-Level executives who are genuinely concerned with the traditional approach to transformation, but this is more a gut feeling that they cannot clearly explain. The big consultancy firms, which are generally in charge of such large transformations, also privately share similar concerns, yet both feel that they have no credible enough alternatives. In the Progressive and Alternative sphere, a lot of experimentation is done on new governance models, but it goes generally undocumented. We found that they experiment only with one or sometimes a few of the aspects that we will share, but not enough, as it is the synergy between the different aspects that we found most helpful.

By providing not only an account of the transformation but also a model to understand it, we intend to provide a basis for discussion and further generative experimentations.

\section{Materials and Methods}

To begin with, we need to clarify what we mean by transformation. Next, we describe the model that emerged during this transformation, that we named the "post-industrial" viewpoint, and contrast it with the common current practice of organization transformation, or "industrial" viewpoint. We go on to detail the post-industrial model in relation to CAS, and how it affect the

\footnotetext{
${ }^{2}$ See 2.5.4
} 
operation of an organization transformation, before presenting results and discussing some of these points.

\subsection{What Is a Transformation?}

\subsubsection{The Netflix Example}

Let's get a closer look at the Netflix example:

1. Before the transformation, Netflix was renting DVD, sending them by post. This was an innovation at that time, when competitors had physical shops. Its core business was distribution: sending parcels ${ }^{3}$ by post, and managing physical warehouses;

2. Afterwards, it became the pioneer of Video On Demand (VOD), and its operations division became a pure IT Business. Different activity, different skills in the workforce ${ }^{4}$.

3. Then Netflix becomes a content producer, producing its own original films.

(1) is not a transformation per se, but innovation at the operating model layer (Level 1 change, see below).

(2) is a transformation of the (internal) method, which retains the market and the customers. The product is the same (entertainment on video), but there is a change in its delivery model (Level 2 change, see below).

(3) the second transformation is a shift into a new business (Level 3 change, see below), and a move from an industrial sector to an artistic sector ${ }^{5}$.

There is an acquisition of new skills (L1), but also the development of a new vision and the ability to see the obstacles to transformation and to overcome them (L2), by understanding the motivations behind these obstacles, and by allowing oneself other choices, in safety.

Note : In the scope of this paper what we means by organization is mature organizations, not startups or small and medium-sized enterprise (SME). The assumptions for the organization as a CAS should still be valid for these, but their focus is on survival and growth, rather than transformation (see ecocycle below). Also, we are focused on typical Productive, For-Profit, companies.

\subsubsection{The example transformation}

This paper builds on the example of an agile transformation in the field of information technology.

The aim of the transformation was to move from a Taylorian organization, structured around skill teams coordinated by managers to (semi-)autonomous, multi-skilled teams, which IT usually calls the "agile" model ${ }^{6}$.

There were three innovations in that transformation. Changing the viewpoint of the organization, the mechanism of diffusion, and the pedagogical content:

- The organization was considered as a complex adaptive system (CAS ).

- The mechanism consisted in the diffusion of new elements within the system by the involved parties themselves, i.e. by playing on the adaptative mechanism,

- The pedagogical content included a large part on the theories of complexity and how to integrate it practically into everyday life in the office.

\footnotetext{
${ }^{3}$ Tapes and DVD

${ }^{4}$ If this sounds "hard", note that all other non transformed competitors are just dead. (BlockBuster, or your local DVD rental company around the corner)
}

${ }^{5}$ Netflix has maintained DVD mailing activities in the US.

${ }^{6}$ A video presents this [11] 
In contrast, the common approaches are traditionally:

- A mechanistic perception of the company, based on deterministic processes operated by human agents and controlled by a command pyramid, mostly treating human agents as "robots". This approach has already shown itself as inefficient for simple reorganization, and fails systematically when applied to transformation.

- A plan is designed by managers with no input from the teams and unfolds in a mechanistic way, which creates a great resistance to change.

- The pedagogical elements that are shared are only focused on the new processes, organization or practice necessary for the new jobs.

\subsection{Working assumptions}

Traditionally, organization are considered as a deterministic entity , controlled from above by a board of directors and a chain of command, like an actual factory. We offer another model here, first listing our working assumptions before detailing them, and finally comparing it with the traditional viewpoint.

We can organize that model around four pillars:

- how we consider an organization

- $\quad$ which systems we are considering

- what we can observe, how, and what acting/enacting means

- what we expect to happen

\subsubsection{Summary of the assumptions}

How we consider an organization:

- An organization is a Complex Adaptative System (CAS)

- An organization is a living system

- It is concerned with growth and development

- An organization is a intentional and self-aware System

- Intrinsic motivation is what create movement (or resistance), for instance the defense of its identity, and the will to develop itself

Which systems we are considering:

- These systems have many layers of subsystems, and should be observed at several levels: individuals, teams, groups of teams ( up to a company division), strategical (board of directors))

- Outside and inside: being self-aware, systems have to be considered both from the outside, that is, how they behave, and from the inside : how they think, what motivates them, what they believe is possible (or authorized), what knowledge and abilities they have, and how they consider themselves (intentionality?)

- Two basic needs of these systems are important to consider for development: integrity/security and clarity. Without security, the systems will freeze or flee, and without enough clarity the systems will not goes forward (whichever direction forward lies)

- To change a system's behavior, we have to change the way it considers itself, what it think is possible, and what motivates it. In other words, develop a new viewpoint.

What we can observe, how, and what acting/enacting means:

- Observations are informational rather than physical

- When in emergence, confusion reigns. We can bring clarity through the use of a few taxonomy ladders. 
- To boost development, new viewpoints should be introduced, both to gain new capabilities and to allow the system to move beyond its current viewpoints (notably how it views itself and its environment). These are provided, but not forced upon the system.

- Structure and repetition are necessary for these viewpoints to anchor and last.

- Changes in self-perception generate a change of mindset.

- The mindset types have to be named and categorized to be shared, recognized, and permit evolution between types (this is the spiral dynamics)

- Behaviors should be considered, but also motivations, meaning values and beliefs

- Climbing the spiral require 6 criterias to be met

- Dealing with qualitative changes and emergence

What we expect to happen:

- Transitions are non linear

- They follow an S curve

- To boost diffusion, create and maintain a peer-to-peer network, and stimulate it.

- $\quad$ Shift to a post-industrial paradigm

This is easy to understand when applied to a human individual, but this works also for the other levels considered (teams, divisions, strategy). We will now go into more detail, and contrast it with the common practice.

Disclaimer : in what follows, we try and explain our assumptions, and relate them to existing works. There is no intention to prove them valid.

\subsection{How do we consider an Organization}

Organization are Complex Adaptive Systems, living systems, they grow and develop, and are intentional and self aware.

\subsubsection{Organizations as Complex Adaptive Systems}

Turner and Baker [12] propose eight characteristics of complex adaptive systems from the literature. We tested these characteristics in the context of an organization, and each of these eight characteristics has shown to be present:

- Path dependent: systems tend to be sensitive to their initial conditions. The same force might affect systems differently.

- Systems have a history: the future behavior of a system depends on its initial starting point and subsequent history.

- Non-linearity: react disproportionately to environmental perturbations. Outcomes differ from those of simple systems.

- Emergence: each system's internal dynamics affect its ability to change in a manner that might be quite different from other systems.

- Irreducible: irreversible process transformations cannot be reduced back to its original state.

- Adaptive/Adaptability: systems that are simultaneously ordered and disordered are more adaptable and resilient.

- Operates between order and chaos: adaptive tension emerges from the energy differential between the system and its environment.

- Self-organizing: systems are composed of interdependency, interactions of its parts, and diversity in the system. 
Organizations being CAS means you can expect homeostasis, feedback and feed-forward loops, etc. You cannot expect them to be deterministic and predictable.

This contrasts with the common viewpoint which is to consider them as deterministic, mechanical entities, predictable, like factories. We elaborate on this later as the "industrial paradigm".

\subsubsection{Organization as living systems}

Bricage [13] gave 7 criterias that are sufficient and necessary to qualify a systems as a living system. This is easy to understand on actual living organisms, but it also applies well to other systems, ranging from particles to galaxies.

1. The capacity to mobilize flows of matter and energy (incoming flows: inputs, internal flows: throughputs, outgoing flows : outputs), from which all other capacities stem.

2. The capacity for mass growth (accumulation, internal or external).

3. The capacity to respond (react) to stimuli (of external origin, coming from the ecoexotope ${ }^{7}$, or internal, coming from the endophysiotope); this capacity intervenes in the processes of coordination and regulation of the other capacities.

4. The capacity to set up (and maintain) an internal organization over space and time (the endophysiotope is a space-time-action).

5. The capacity of outside integration, of adequacy between the endophysiotope's capacity to be hosted and the capacity of the survival ecoexotope to be hosted (these 2 fields of space-time-action being inseparable and in continuous interaction and feedback).

6. The capacity of movement, passive or active, internal or external.

7. These capacities enable survival, which is the prerequisite for the establishment of the capacity to survive, to reproduce its life form, with or without growth in numbers.

It matches well with our observed systems: human (living organism), but also teams, divisions, .. organizations (or any socio-ecological system, in fact).

\subsubsection{Organization as intentional and self-aware systems}

We assumed that organization have:

- Self-awareness

- Intentionality

According to the following definitions :

- "While consciousness is being aware of one's environment and body and lifestyle, self-awareness is the recognition of that awareness. Self-awareness is how an individual consciously knows and understands their own character, feelings, motives, and desires". [14]

7 Endophysiotope, Ecoexotope: the inside functioning space, the outside space of inhabitation: Into our organism (the Whole), our cells (the actors), like in the swarm itself, all are functionally defined by their endophysiotope (ENDO: internal, tope: space, physio: of functioning) and their ecoexotope (EXO: external, tope: space, eco: of inhabitation), that together define the system as a Wholeness, and the interface of exchange between ENDO and EXO .-- Bricage [13] 
- Intentionality is a philosophical concept defined as "the power of minds to be about, to represent, or to stand for, things, properties and states of affairs". [15]

Companies do "stand for, things, properties and states of affairs", their own ones, and where their interests lies ( intentionality).

An Organization has "to be aware of its environment", its offices and factories implementation, and "lifestyle" (its culture, impact on environment, social responsibility). Mature organizations as well as startups spend a considerable amount of time figuring their vision, strategy, and so on.. ( motives and desires).

While vision often happens at the board level, this is not so common to develop a vision at the team level, which usually defines itself by its outside utility or responsibility to its internal clients, more than its own internal motivation.

\subsubsection{Internal motivation versus external force}

What makes things move is the external force in a mechanical world, and the internal motivation in a complex world:

Pirotton [16] explains the difference as such :

- A billiard ball that hits another ball transmits a certain energy to it, which makes it possible to predict its movement. The mechanical mode is thus dominated by the play of forces, impacts, energy transfers. This makes it possible to understand and predict the phenomena of this world. Of course, an observer will be able to describe these phenomena, observe regularities, deduce laws ...

- If the billiard ball moves, it's because we hit it correctly with the ad-hoc stick. We thus attribute ourselves at the same time the status of cause of the observed change.

This is the affirmation of Identity, for Pirotton: "We can thus see, in our very refusal to allow ourselves to be determined in this way from "outside", one facet of the affirmation of our identity. It is this "competence" of complex systems that we must recognize here" [16]

This identity stems from a conception where:

- The subject occupies the central place in its environment

- The subject evaluates itself by measuring its capacity to act on its environment.

- This capacity for action is combined with a willingness to control, which is assimilated to the capacity for external control. 8

A living system continuously create itself, this is the Autopoesis from Varela [17]:

"Autopoiesis differs from what has been called, since the eighteenth century, generation, in that it does not concern the production of another system or organism (reproduction) but defines the establishment and maintenance of one's own organization (self-production) by the system or organism in question."

8 linked to Dilts Levels: In other words; the systems evaluate its capacity (D3) to act (D2) on its environment (D1). This combine the willingness (D4) and what is believed as possible (D4) : this is its Identity (D5) 
This opens up two possibilities to approach "system change":

- You help the system develop; when the system develops, and creates new capacities (D3), it "updates" its beliefs (D4) and identity (D5), too. This implies you consider the systems as being a living, adaptative system.

- You use forces, impacts, energy transfers. You consider the system as mechanical, predictive, an object you can manipulate.

If you use the second option on a living CAS, it will trigger "resistance to change", as the system "refuses to be determined from "outside"," and it considers this a thread to its Identity (D5).

So far, we considered that Organization are CAS, living systems, and are intentional and self-aware. We will now clarify which subsystems we consider, and how.

\subsection{Which systems we are considering}

The system is composed of several level of organization', each being observed outside and inside. We consider it both from a quantitative and qualitative aspect, as we expect new properties to emerge, and the system to stabilize by integrating them properly.

\subsubsection{Many Systems}

The system is composed of several levels of organization (individual, teams, groups of teams, strategical (board of directors ${ }^{10}$ ), and they each belong to a different category of systems. Observation should be conducted at every level and actions should be enacted differently at every level (still being congruent).

\subsubsection{Outside and Inside.}

Being self-aware, systems have to be considered not only from the outside - that is, how they behave, what they do - but also why and how they do it, how they think, what motivates them, what they believe is possible (or authorized), what knowledge and abilities they have, how they consider themselves ( intentionality?).

This is the Ladder of Dilts.

For example, a team should not be considered as a black box, its input and its output, but looking inside, how its member interacts, what level of information they exchange, and the quality of relation they exhibit. For instance, are they cooperative? Competitive? Which level of authenticity is present? Etc.

\subsubsection{Integrity/ Security and Clarity.}

Two needs are particularly important regarding development: security and clarity.

\footnotetext{
${ }^{9}$ The notion of scale is also used in the CAS domain, but we will use this word in a different meaning afterward ladder : ( collection of related distinction)

${ }^{10}$ We name them : sociological levels [18]
} 
- security (survival/ integrity) is predominant, because until it is met, no other need can take precedence.

- clarity: until enough clarity is reached, the system freezes and cannot evolve significantly (for instance, it oscillates between the security of the present, and the uncertainty of the future)

In other words, the system will not change until it is safe enough, and has enough clarity . It is important to include this in the mechanism of diffusion and develop the appropriate skills for this.

\subsubsection{Systems grow and develop}

Bricage [13] also point an important distinction about quantitative and qualitative.

- Growth is by definition a quantitative phenomenon, of accumulation (or de-accumulation: decay)

- Development is by definition a qualitative phenomenon, the appearance of new properties and/or the disappearance of old properties. It is a journey, step by step. These emerging properties may lead to new capacities.

- Transformation : the change of state, the leap from one stage to the next is an all-or-nothing process and usually involve a threshold : reaching a critical mass, a minimum growth stage, is a usual prerequisite

Organizations are mainly concerned with the productive aspects, and growth. This is the reign of quantitative and figures, illustrated by KPI \& Statistics (Key Performance Indicators), and "scientific management" (Taylor, Fayol). Qualitative aspects are often below the radar of the board of directors, and when present, they are tentatively converted in numeric and KPI, which all but obliterates the qualitative nature, and the emerging aspect, as discussed later.

We assert that transformation is more about development than growth, more about qualitative aspects than quantitative aspects. Enough development should be conducted so that emergent properties appears on several level of organizations.

\subsection{What Can We Observe, How, and what means Means Acting / Enacting}

\subsubsection{Observation}

Most observations are informational rather than physical, and more qualitative than quantitative.

In a factory you can observe the physical flow of material being processed and assembled and workers moving around.

In IT you cannot. At the end of the chain you have some code, but in the early stage you have mainly specification and design documents, in which the quantity of pages or signs does not give an indication of the quality. Agile seeks to have more human interaction and fewer documents, which makes it even harder to observe.

On a team level or at the individual level, you can observe human interactions, and how things are organized. But we needed to qualify the different types of information, establish categories, and then establish distinctions on what the information means to the systems.

Several distinctions, grouped in a ladder or scales were used during this transformation, some reused, some invented, some re-invented before being discovering similar, existing one in the literature. 
We share these, as they are transmissible elements of language, and a seed of culture.

\subsubsection{Ladders and scales}

These are conceptual systems, looking for explanatory power [19], create a common language, and some kind of bearing about the emergence of a concept.

With these we were able to establish a common language, and build representations, tools, actions :

- Level of thought,

- Level of change

- Autonomy

- Mindset

- Mastery

- Emergence

- Sociological level

The application of these are interrelated, for instance, autonomy is conditional to a minimal level of skill (mastery), and require a proper mindset.

This reduces confusion, permits order, and allows emergent properties to stabilize (become robust) by providing clarity.

\subsubsection{Dilts - the logical level of thought}

Dilts shows that the thoughts do change of nature, and he proposes a non-strict taxonomy [20], later adapted for organizations [21]. In the rest of the document, we use D1 to D6 to point in the category. Where D1 to D3 are 'visible' or observable, D4 to D6 are very much 'inside' the mind of an individual. In an organization, the common beliefs and values are called the 'culture' of the organization, 'the way we do things here'. [22]

Table 1. Dilts - Logical level of thought.

\begin{tabular}{ccccc}
\hline Levels & Dilts & Question & organization & \\
D6 & Vision & $\begin{array}{c}\text { What for, } \\
\text { who } \\
\text { Who }\end{array}$ & Vision & Ecosystems \\
D5 & Identity & Mission & Needs \\
D4 & Beliefs/values & Why & $\begin{array}{c}\text { Permission / } \\
\text { Motivation }\end{array}$ & Culture \\
D3 & Capabilities & $\begin{array}{c}\text { How, how } \\
\text { much }\end{array}$ & Direction & Principles \\
& Behaviours & What & Actions & Practices \\
D2 & Environment & Where, when, & Constraints & Tools \\
& & with what & & \\
\hline
\end{tabular}




\subsubsection{Bateson - The Ladder of Change}

There are several types of changes. We used Bateson's learning levels [23] on an individual, then on an organization [24]:

- If in the face of an obstacle, we draw on our existing behaviours, reflexes, habits, then there is no learning, this is Bateson's Level 0 (L0).

- If a new behaviour is exhibited, learning has taken place, a new skill has been acquired. This is level 1 (L1). It is learning as we know it, at school or in vocational training, acquiring ${ }^{11}$ new competences and qualifications, and integrating them.

- If this requires restructuring one's framework of thought, one speaks of Level 2 (L2). The individual observes himself/herself thinking and acting and can allow him/herself new choices. A new frame of thought is created, this is reframing.

- If this leads to a view of oneself or to reconsidering the context, one speaks of Level 3 (L3), or transformational ${ }^{12}$.

Dilts [26] states that:

- Level 1 learning involves skills,

- Level 2 is about beliefs ${ }^{13}$ and values ${ }^{14}$,

- $\quad$ Level 3 is about identity ${ }^{15}$, deeper motivations, foundational needs.

We later mapped the Bateson Level to Dilts, and other authors dealing with Level of change Dilts [26], Beck and Cowan [27], Hollings/Hurst \& Zimmerman (Ecocycle) [28] and two other ladders we created the ladder of Creation and the Organizational Change-Level

Table 2. Levels of Changes.

\begin{tabular}{|c|c|c|c|c|c|}
\hline Bateson & Dilts & $\begin{array}{l}\text { Beck \& } \\
\text { Cowan }\end{array}$ & Ecocycle & Taesch - Creation & Taesch - Organizational \\
\hline Learning 3 & $\begin{array}{l}\text { Identity } \\
\text { (needs) }\end{array}$ & Deep change & Exploration & Creation & Transformation - Model \\
\hline Learning 2 & Beliefs/values & $\begin{array}{c}\text { Challenging } \\
\text { mindset }\end{array}$ & $\begin{array}{c}\text { Release/ } \\
\text { Exploration }\end{array}$ & Innovation & Transformation - method \\
\hline Learning 1 & Capabilities & $\begin{array}{l}\text { Upgrade the } \\
\text { means }\end{array}$ & $\begin{array}{l}\text { Development/ } \\
\text { Growth }\end{array}$ & Improvement & Project - new tool \\
\hline Learning 1 & Capabilities & $\begin{array}{c}\text { Reform the } \\
\text { process }\end{array}$ & $\begin{array}{l}\text { Development/ } \\
\text { Growth }\end{array}$ & Improvement & Program - reorganization \\
\hline Learning 1 & Capabilities & Fine tune & Maturity & Optimization & Quality \\
\hline Learning 0 & Environment & No learning & Maturity & Production & \\
\hline
\end{tabular}

In current management practice ${ }^{16}$, the focus is very much on maintaining the production, optimizing it, and some degree of improvement, as pioneered in Lean. What entails innovation and

\footnotetext{
11 as an addition, not as a replacement for previous achievements

12 this corresponds to single, double or triple loop learning in argyris. [25]

${ }^{13}$ what $\mathrm{i}$ believe is possible, what $\mathrm{i}$ believe is allowed

${ }^{14}$ what i prefer, how i decide, what motivates me

15 roles, and limits
} 
creation is very alien to mature organizations. Most organization have a Quality Department, buy new tools, or undergo reorganization. But these are 'more of the same things', to use Watzlawick's distinction [29], not 'something different'.

To use a metaphor, a project is like 'a shopping list for Saturday errands', a program like 'building a new house' and a transformation like 'losing weight'. The first two are something you could externalize, delegate. You are just interested in the outcome. Your shopping is at home, your house is built. But 'losing weight' is something which you have to go through, personally, it cannot be delegated.

Table 3. Levels of Changes.

\begin{tabular}{|c|c|c|c|}
\hline Bateson & Taesch-Creation & Taesch - Organizational & Watzlawick \\
\hline Learning 3 & creation & Transformation - Model & $\begin{array}{c}\text { Something } \\
\text { different }\end{array}$ \\
\hline Learning 2 & innovation & Transformation - method & $\begin{array}{c}\text { Something } \\
\text { different }\end{array}$ \\
\hline Learning 1 & improvement & new tool-project & $\begin{array}{c}\text { More of the } \\
\text { same }\end{array}$ \\
\hline Learning 1 & improvement & Reorganization - program & $\begin{array}{c}\text { More of the } \\
\text { same }\end{array}$ \\
\hline Learning 1 & optimization & Quality & $\begin{array}{c}\text { More of the } \\
\text { same }\end{array}$ \\
\hline Learning 0 & production & & $\begin{array}{c}\text { More of the } \\
\text { same }\end{array}$ \\
\hline
\end{tabular}

Transformations is something that affects the beliefs and values (D4) or even the identity (D5), i.e. what we think is possible (L2), or the way we consider ourselves (L3). In the Netflix example, Netflix changed its operating model to deliver Video on Demand when they were shipping boxes before. This was a transformation from the sector of distribution to the sector of IT services. (L2)

Later it went into the production of its own films, which is a step into the show business sector. This is a transformation of an even higher order, touching the business model, the identity (L3).

Table 4. Netflix Levels of Changes.

\begin{tabular}{|c|c|c|c|}
\hline $\begin{array}{l}\text { Level of } \\
\text { Change }\end{array}$ & Taesch - Creation & Taesch - Organizational & Netflix \\
\hline Learning 3 & creation & Transformation - Model & $\begin{array}{c}\text { Producing } \\
\text { Movies }\end{array}$ \\
\hline Learning 2 & innovation & Transformation - method & VOD \\
\hline Learning 1 & improvement & new tool - project & Shipping Boxes \\
\hline
\end{tabular}

2.5.5 Mindset - Graves - Spiral Dynamics

How can we categorize mindsets? These are a group of coherent beliefs of values (D4).

16 The focus is on mature organizations, not startups or SMEs. 
Graves produced a ladder of 'mindset'17, [31]. Later Beck and Cowan [27], named it 'spiral dynamics', used it for leadership and Laloux for organizational design [32].

Besides the ladder of mindset itself, this is a series of principles to explain the mindsets formation, and obstacles to development:

- These levels are built on top of one another, being antagonistic to the extremes of the predecessor. (Ago - antagonism.)

This is summarized by the saying:

Problems cannot be solved by the same level of thinking that created them - A. Einstein

Graves identified 6 criteria [33] that are necessary to be able to rise to a new level, and what might lead to instability when doing so. Literally, acquiring/building gaining a new mindset is a transformation (L3), as it touches the identity (L3) (D5) on top of beliefs and values (D4). Its prerequisite $(\mathrm{C} 0)$ is that the system is in an open state (and not closed or arrested i.e. frozen).

It applies to individuals and groups (psychogenesis and sociogenesis).

We used the spiral dynamic ladder as a language to describe mindsets, individual or group dynamics, and also the mechanism to facilitate 'climbing this ladder'. We also believe that acquiring higher mindset require finer distinctions [34] (that were provided via a series of ladder of distinctions).

\subsubsection{Ecocycle and Panarchy}

Another way to model the levels of change is to relate it to the creation-destruction phases.

C. S. Hollings [35] has modelled in its adaptive cycle the birth of growth to maturity followed by a phase of deconstruction. Hurst and Zimmerman [28] apply this to organizational management, and show the four types of management of the four quadrants, in their 'eco-cycle'.

It is important to see that the properties displayed are antagonists and, moreover, there are traps [36] that will prevent easy switching from one quadrant to another (attractors), such as the one between Maturity and Release.

17 Or vmeme ( value meme) referencing Dawkins [30], who defined the meme as a unit of cultural transmission, or a unit of imitation and replication 


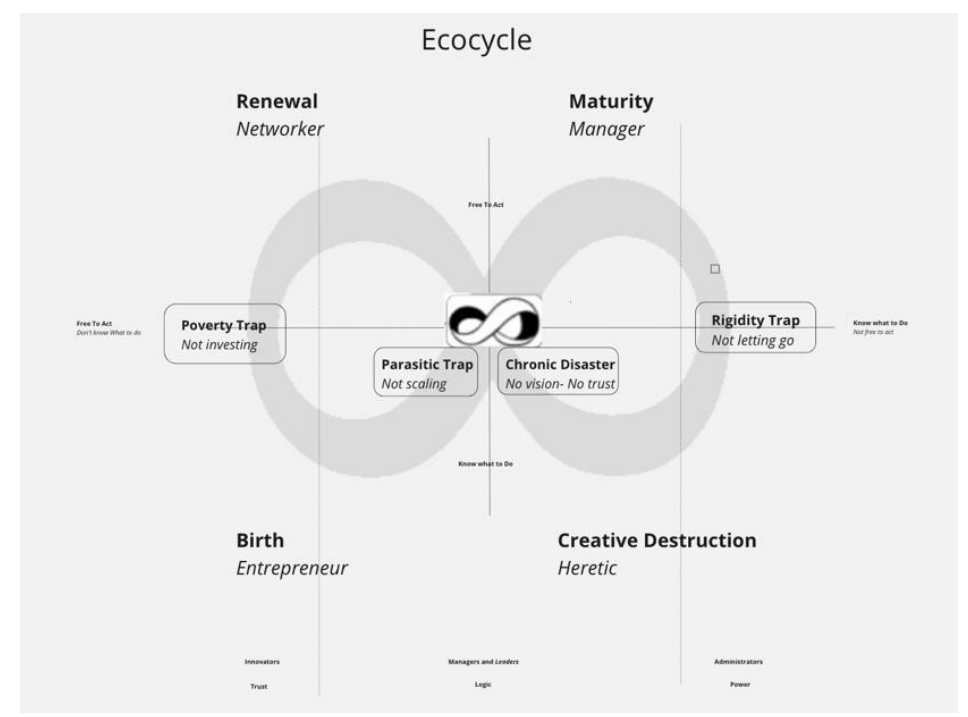

Figure 1. the four quadrants of the ecocycle, and the management associated

Start-ups, SME and mature organizations are on the Front Loop, the growth Part of the Cycle. They get more and more structured to sustain their growth.

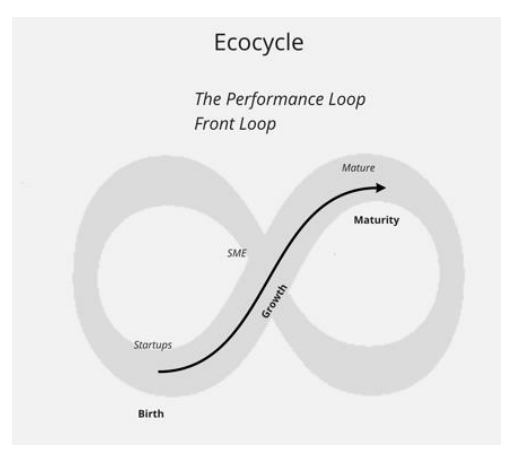

(a)

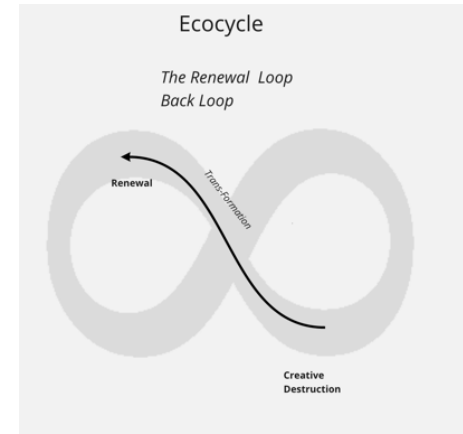

(b)

Figure 2. (a) Start-ups, SME and mature organization are on the Front Loop; (b) Transformation is on the back loop.

It is important to understand that a transformation (change of form) is located on the back of the loop. Most mature organizations dream about 'being a start-up again', i.e. taking the front loop backwards.... They have to realize it goes through the Release then Exploration phases, i.e. let go of most of the structures that were built to bring them to maturity.

The 'Maturity Trap' is when the system cannot let go of its old structure to undergo renewal. Imagine the caterpillar refusing to let go of its old habit, then it cannot transform into a butterfly.

Gunderson \& C.S. Hollings has also worked on the inter relation between layers of the panarchy system [37] by showing that the lowest layers favor evolution of the layers above and higher lever "remembers" at re-creation time. 


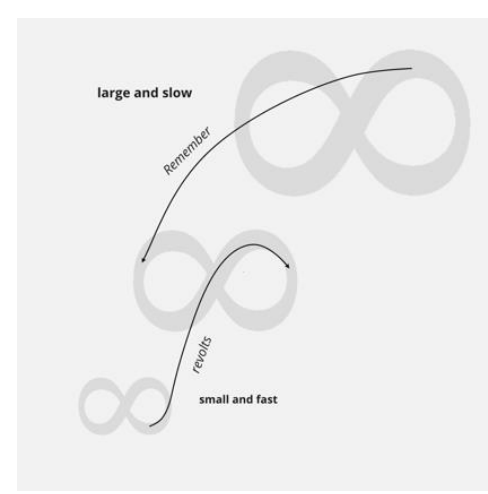

Figure 3. panarchy: the system in the middle is 'accelerated' by is subsystems, and 'slowed down' by super-systems.

Hollings et al. identify three types of change within panarchies: incremental change in the birth and maturity phases (L1) which are smooth and fairly predictable; abrupt change in the release phase (L2) and; and transformational learning (L3), meaning change involving several panarchical levels [38]

If we apply this to organizations, this means that the evolution and transformation of groups will be influenced by the evolution and transformation of its individuals and slowed down by the strategic layer above it.

In other words, it is necessary to create synergistic conditions, and then influence all the sociological levels.

Allen warns that: [39] 'Regime changes occur when a system's resilience threshold is crossed and the processes responsible for a system's structure and function change and create new self-organized structures. It is not the norm for the destruction cycle within an adaptive cycle to result in a regime change.

The reorganization phase of the adaptive cycle is likely to simply reorganize around the same structures and processes, in which case a change in systemic structure has not occurred.'

\subsection{What do We Expect to 'Happen'}

We expect systems to develop new properties, new capabilities, change beliefs and values, or even identities (D3-D4-D5). We expect existing forces to be antagonists, and slow down evolution (homoeostasis). We expect self-reflexivity to be necessary to cooperate with the evolution. We expect the transition to be non-linear, and to be fragile before the inflexion point of the S-curve.

\subsubsection{Develop New Viewpoints}

We expect systems to develop new properties, new capabilities, change beliefs and values, or even identities (D3-D4-D5).

The system limits itself depending on what it 'thinks' is possible (belief, D4). By developing new practices (D2), in the community of practices for instance, and acquiring new concepts (D3), it will change its beliefs on what is possible or not (D4). It should also be 'safe enough to try' i.e. authorized (D4) by whatever is perceived as a superior authority. 
During the development, contradictions and ambiguity may surface, for instance, between the set of old and new rules, or between old and new values, like Pisano illustrated [40]:

- A tolerance for failure requires an intolerance for incompetence.

- A willingness to experiment requires rigorous discipline.

- $\quad$ Psychological safety requires comfort with brutal candor.

- Collaboration must be balanced with an individual accountability.

- And flatness requires strong leadership.

'Innovative cultures are paradoxical. Unless the tensions created by this paradox are carefully managed, attempts to create an innovative culture will fail.'

To boost development, a new point of view should be developed (in fact, provided) to 'free' the system from its current viewpoints, and enable them with a new viewpoint ${ }^{18}{ }^{19}$ [41].

For instance, reaching a decision is often a mess in teams. Decision modes can be consensual and revert to directivity when stalled, yet there is no real clarity about the tipping point. To challenge this, we provided a ladder with 4 modes of decision, ${ }^{20}$ qualify them from the more directive to the less directive and discussed which is appropriate when. Then we practised consent and agreed to use it as the default mode ${ }^{21}$. From then on, the participants had clarity on how they were deciding (concept-D3), and why (D4). The new mode was more efficient, especially for complex decision.

This gradually diffused in the organization ${ }^{22}$ and helped opening a new mindset ${ }^{23}$.

This is an application of Buckminster Fuller saying:

'You never change things by fighting the existing reality.

To change something, build a new model that makes the existing model obsolete.'

\subsubsection{Transitions are non-linear}

These new viewpoints will not propagate instantaneously through the organization. It will be gradual, and non-linear. We believe it follows rather an S-curve [42], like most of the propagation of 'innovation' in culture. [43]

The first inflexion point is important:

- After this point, it is inevitable.

-Before this point, it is fragile.

18 By viewpoint we mean here, D4 belief and values and D5 identity plus D6 vision i.e. the way I see me in the world

19 This is an application of social constructivism, which concept, once it was shared, eased the switch of mindsets, and departed from the realist position that technical people have often by default.

${ }^{20}$ Directivity, compromise, consensus, consent.

21 in non crisis situation

22 but at the level it was seeded (team), not above (strategy) . this level was seeded later, separately .

${ }^{23}$ In fact the 4 modes we associated with 4 level of mindset in spiral dynamics, and by using consent, they were jumping "ahead" 


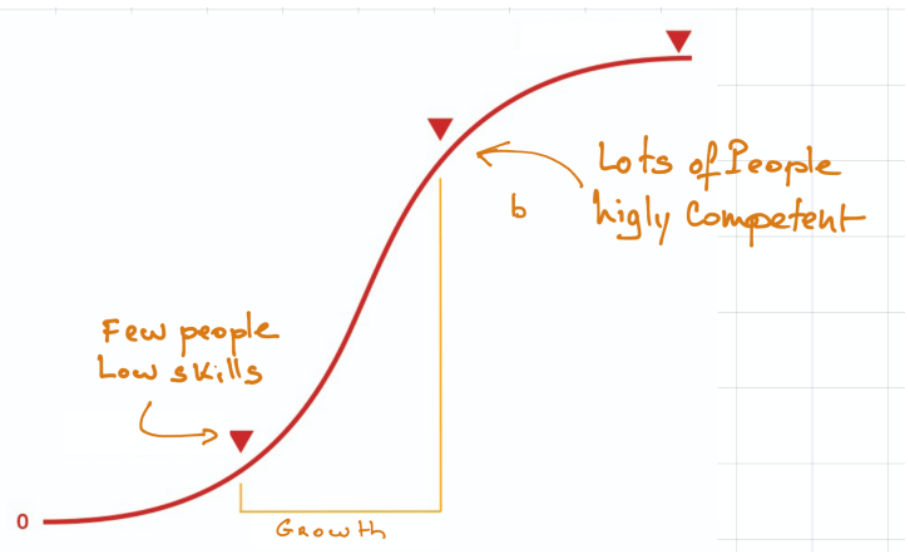

Figure 4. diffusion. The two inflexion points, the first one is the 'tipping point'.

At the beginning, there are few people, not well trained, not very competent. In the end, many people, well trained, very competent. (Note: there are a quantitative aspect and a qualitative aspect.)

After the inflexion point, it is inexorable.

Before the inflexion point, it is fragile, and must be 'cultivated' and supported.

This is found in popular wisdom in the form of sayings reflecting societal shifts: Gandhi

'First they ignore you, then they laugh at you, then they fight you, then you win.' - Mahatma

'Never doubt that a small group of thoughtful, committed, citizens can change the world. Indeed, it is the only thing that ever has.' - Margaret Mead

However, one must not fall before reaching this tipping point.

\subsection{Post-industrial paradigm versus industrial paradigm}

We do expect a lot of confusion also, as some principles we introduce are antagonists to principles in place. If this is not tackled, the transformation freezes.

- Confusion between incertitude and risk management

- Confusion between improvement and innovation and between production and creation

- Confusion between innovation and agility (adaptability)

- Confusion between 'rigid' vision, program implementation and emerging vision

All these are consequence of a mistake we often see implementing a 'post-industrial' organization in an 'industrial way' [44]. Or to simplify it: trying to introduce 'agility' in a rigid and predictive, mechanist way.

As such, we find significant that the latest fad for mature organization is to recreate a separate IT department from scratch, generally after the failure to transform the existing IT department, and call it a 'digital factory' [5], i.e. anchoring it very clearly in the industrial mindset... 
Table 5. contrasting industrial and post industrial. See [44].

\begin{tabular}{cc}
\hline Mature/industrial & Post industrial \\
\hline To conserve & Emergence \\
Focus on growth & Develop/adapt/transform \\
Quantitative & Qualitative \\
Mechanical and predictive & Non-linear, Emergent \\
Risk adverse & Accept to Live with Uncertainty \\
More of the same thing & Something Different \\
Infinite growth & Embracing transformation including \\
More structure and forms & DE-structuration \\
Monolith/silos & Let go of (existing) structure \\
Organization is an Object/passive & Composite of systems \\
Prefer simple and complicated & Self-aware \\
\hline
\end{tabular}

\section{Results}

Bearing in mind the model of an organization as a CAS, we needed to operate at multiple levels, and stimulate them for development. Once we had our first results, the condition for replicating and auto similarity were to be stimulated too, for the diffusion to gain momentum.

[More detailed information, including the company, detail chronology, and techniques used are available in conferences or video]

\subsection{Evaluating the results}

Mid Year 2 of the transformation, we wondered how we could assess our transformation progress, and also see what could be missing. We compared the state before the start of the current state. It was also compared against say a typical deployment of SCRUM (the more common agile 'method'), and also Sociocracy-Holacracy, which is a trendy 'modern' governance alternative. The first question that arose was: which criteria to use? We first used the SES criteria ${ }^{24}$ [45] [46] that estimate how are 'good' are SES . But alone this was not enough, we were missing finesse (namely, of where the impact lies - personal, team, strategy.). Then we added the sociological levels, which then form an Evaluation Matrix.

Here are the synthetic results. An $\mathrm{x}$ in a cell means that there is 'something' covering this Sociological Level (say Team) for this SES principle (say S2. Connectivity). 'Something' means a practice, a principle, a policy, a community, etc. This is very loose, but it already gave interesting indications of coverage. The data were obtained by asking a panel of managers in multiple blind tests.

${ }^{24}$ integrated systems of humans and nature that constitute a complex adaptive system with ecological and social components 
Table 6. The Assessment of the Division, before the start.

\begin{tabular}{|c|c|c|c|c|c|}
\hline SES/S.Level & Intra-Personal & Inter-Personal & Team & Division & Strategy \\
\hline 1. Diversity-redundancy & & & $\mathrm{x}$ & & $\mathrm{x}$ \\
\hline 2. Connectivity & & & $x$ & $x$ & $x$ \\
\hline $\begin{array}{l}\text { 3. Slow } \\
\text { variables - feedback }\end{array}$ & & $\mathrm{x}$ & $x$ & & $x$ \\
\hline 4. CAS thinking & & & & & \\
\hline 5. Learning & & & & & $x$ \\
\hline 6. Participation & & & $x$ & $x$ & \\
\hline $\begin{array}{l}\text { 7. Polycentric } \\
\text { governance }\end{array}$ & & & $x$ & & $x$ \\
\hline
\end{tabular}

Table 7. The Assessment of the Division, Year 2.

\begin{tabular}{|c|c|c|c|c|c|}
\hline SES / S.Level & Intra-Personal & Inter-Personal & Team & Division & Strategy \\
\hline 1. Diversity-redundancy & $\mathrm{x}$ & $\mathrm{x}$ & $\mathrm{x}$ & $\mathrm{x}$ & $x$ \\
\hline 2. Connectivity & $x$ & $x$ & $x$ & $x$ & $x$ \\
\hline $\begin{array}{l}\text { 3. Slow } \\
\text { variables - feedback }\end{array}$ & $\mathrm{x}$ & $\mathrm{x}$ & $\mathrm{x}$ & $\mathrm{x}$ & $\mathrm{x}$ \\
\hline 4. CAS thinking & $x$ & $x$ & $x$ & $x$ & $x$ \\
\hline 5. Learning & $x$ & $x$ & $x$ & $x$ & $x$ \\
\hline 6. Participation & $x$ & $x$ & $x$ & $x$ & $x$ \\
\hline $\begin{array}{l}\text { 7. Polycentric } \\
\text { governance }\end{array}$ & $x$ & $\mathrm{x}$ & $\mathrm{x}$ & $\mathrm{x}$ & $\mathrm{x}$ \\
\hline
\end{tabular}

The first table (Table 6) is the assessment of the situation before the transformation started, the second table (Table 7) is the assessment of Year 2. We were happily surprised to see such difference.

The figure A1 in annex A gives some examples of what this x means in practice.

We compare it also with what would be a pure agile deployment in SCRUM, the dominant agile methodology in the market (Table 8). Unsurprisingly, it is concentrated on the Team level, but cover none beyond this level. Also, it is mainly based on practices (D2), so provide nothing specific to polycentric governance (but it does provide some 'local' governance light hints), or no CAS thinking (despite the fact that it is inspired by cybernetics, but none is explicated. It does provide feedback loop, though, 'retrospectives' being one example).

Table 8. Agile doctrine, SCRUM.

\begin{tabular}{|c|c|c|c|c|c|}
\hline SES / S.Level & Intra-Personal & Inter-Personal & Team & Division & Strategy \\
\hline 1. Diversity-redundancy & & & $\mathrm{x}$ & & \\
\hline 2. Connectivity & & & $x$ & & \\
\hline $\begin{array}{l}\text { 3. Slow } \\
\text { variables - feedback }\end{array}$ & & & $x$ & & \\
\hline 4. CAS thinking & & & & & \\
\hline 5. Learning & & & $x$ & & \\
\hline 6. Participation & & & $x$ & & \\
\hline $\begin{array}{l}\text { 7. Polycentric } \\
\text { governance }\end{array}$ & & & & & \\
\hline
\end{tabular}

The same exercise with Sociocracy show this doctrine is focused on the governance and team organization aspects (Table 9).. 
Table 9. 'Dynamic Governance': Sociocracy-Holacracy.

\begin{tabular}{|c|c|c|c|c|c|}
\hline SES/S.Level & Intra-Personal & Inter-Personal & Team & Division & Strategy \\
\hline 1. Diversity-redundancy & & & $\mathrm{x}$ & & \\
\hline 2. Connectivity & & & $x$ & & $\mathrm{x}$ \\
\hline $\begin{array}{l}\text { 3. Slow } \\
\text { variables - feedback }\end{array}$ & & & $x$ & & $x$ \\
\hline 4. CAS thinking & & & & & $x$ \\
\hline 5. Learning & & & $\mathrm{x}$ & & $x$ \\
\hline 6. Participation & & & $x$ & & $x$ \\
\hline $\begin{array}{l}\text { 7. Polycentric } \\
\text { governance }\end{array}$ & & & $x$ & & $x$ \\
\hline
\end{tabular}

The lack of wider coverage was an explanation in our eyes why a pure agile deployment (SCRUM) (or pure Sociocracy) may well fail, as one level of the ecosystem is supposed to change, but nothing is facilitated by the other ones, which may then exhibit homeostasis, i.e. 'resistance to change' from an exterior influencer.

This exercise gave us the appetite for more qualitative evaluations. Instead of just testing for the existence of a structure, we assessed the Maturity Level of this structure, using spiral dynamics, after and before.

For instance, the S5.Learning was covered originally in top down central manner, managed by HR. ${ }^{25}$ Later on, there were self-learning peer networks ${ }^{26}$ and even cells learning CAS ${ }^{27}$.

\subsection{Seed Team}

A first team was given full attention and coaching, and raised through the 4 levels of autonomy [47] in 1,5 years. It became autonomous enough after 3 months, recognized as the 'exemplar' team after 6 months. Later, the lead of this team was nominated at the head of a new practice created to replicate this 'model' on other teams. To compare with 'market practice', coaches are happy when a team reach level 3 (agility) in 2 to 3 years. Level 4 (self-direction) is not even expected in the market. And this despite the team was split on two sites (Lille/Nantes) and met physically only every 3 months.

We think this was possible thanks to the synergy of working on several levels simultaneously (individual, team, strategy), and focusing on one autonomy level at a time (Erden ladder); providing time for integration and stabilization, plus the clarity provided by self-reflection, non-violent communication, building a language for self-analysis, and collective vision building.

Practically, on the interaction level, we introduced: distributed control, equivalence in control, parole, structure and clarity, meaning, impact.

From the beginning, interactions were structured to favour psychological safety, i.e. empathy, respect and equivalence [48]:

- A one-hour status and review meeting was organized every other day. Two roles were nominated: one facilitator, one secretary. These roles were turning, i.e. assigned to someone else

\footnotetext{
${ }^{25}$ SD: Blue

${ }^{26} \mathrm{SD}$ : Green

${ }^{27} \mathrm{SD}:$ Yellow/Teal
} 
every session. The assignment was on a voluntary basis. Nobody tried to shy away. The interaction was following an established (and written) protocol. The facilitator was making sure that impromptu divergent problem-solving discussion was either quick, or respawn after the core meeting, in a separated dedicated meeting. So that the status meeting stayed effectively convergent.

- All the information was available visually on a virtual board, accessible by every team member in parallel (no centralized control). The information was showing plan information, technical elaboration, technical problem solving, and also goal and user needs (Meaning), in a textual and graphical manner. It also included daily progress and meeting minutes, with all these in macro to micro levels in a single place, no spread among a dozen tools and places [49] (Clarity, Transparency)

- When divergent interactions were taking place, Liberating Structures [22] were systematically used. 124, troika, instead of open talks or managed talks (decentralized control) [50]

- Every 3 Month, a session was organized over 3 days, colocating the full team to have a retrospective, plan ahead, reflect on interaction both inside and outside the teams, and share emergent meaning to turn them into objectives. It also included risk sharing with possible mitigation, reviewing and adapting the internal procedures and workflow, and also individual morale, motivation and well-being

- Every 6 month, a review with board members, to plan, budget, and validate the overall objectives for the next 6 months. Practically, the next iteration was based on a bottom-up proposition, coming from the team, approved by the board, not the other way (except the initial iteration, when creating the mission and team).

- The use of Dilts boards [51], and decision by consent, permitted talks about belief and values.

All three Level of interaction was covered explicitly, and modelled: individual, team, and organizational. (Figure 5.) Tools, practices, skills, values and beliefs, objectives were exploited (Dilts levels). As it was a lot to digest, this was spread over time (one Erden Level at a time).

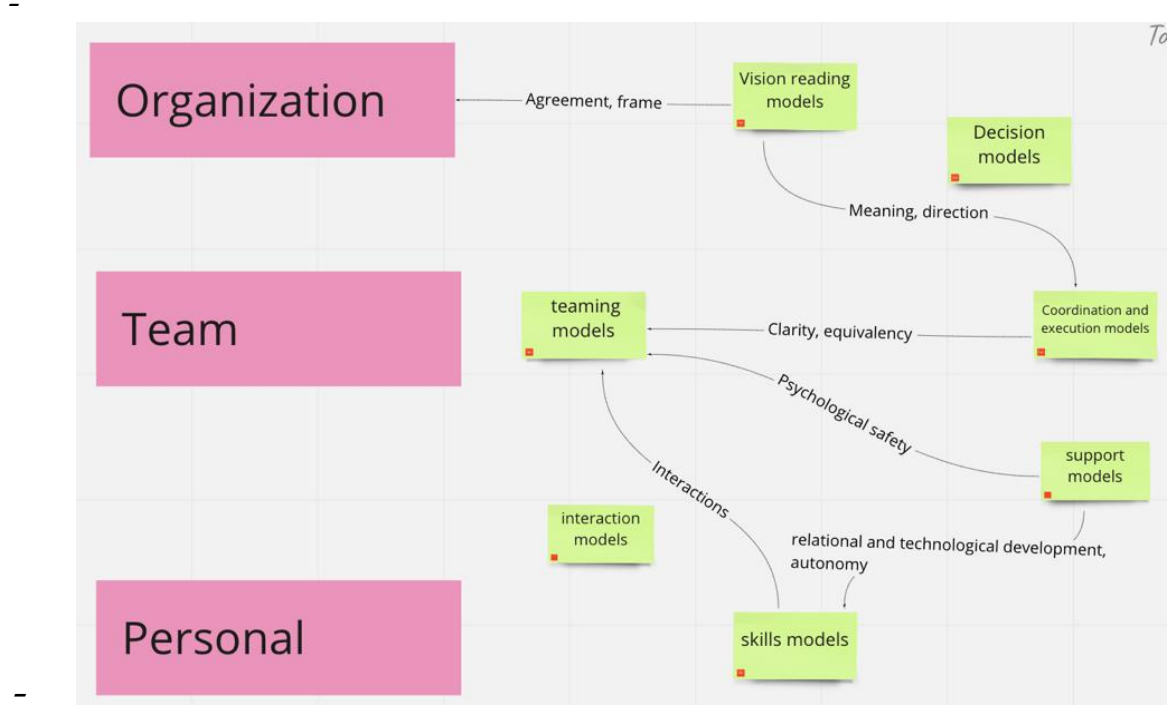

Figure 5. all aspects of team interactions should be covered, (3 levels of coverage for a team: personal, team, organization), inside and outside, with explicit models

- For instance, during the first level, focus was set in creating team discipline and safe interactions. The team was digesting it by practicing it every other day during the meeting. At the inception, the coach was doing it himself, then another individual tried and copied (under supervision and feedback of the coach), and then turning roles were initiated, so everybody, in turn got the role and then practiced it (under supervision and feedback both of the coach and its peers). 
- During this first iteration (3 months), vision (organization level) was created by the coach and tech lead. In the second iteration ( 3 months), focus was on autonomy. Vision was created by the tech lead with input from the team, supervised by the coach. In the 3rd and subsequent iterations, vision was created by the team, collectively, supervised by the tech lead, without coach involvement. (Erden 2 to 4.) This gave them time to absorb other skills, and get clarity before ingesting the skills of visioning, the more abstract of the 3 levels.

- This gives an overview of the tactics: a/ the coach leads by example, b/ the coach start transmission to one or two motivated pioneers, that start acting under supervision, c/ pioneers start transmitting themselves, the coach withdraws from action, and just helps the new transmitters.

- The progression was perceived as fast on the outside of the team, but OK within the team. We attribute the speed to the fact that aspects were practiced first, then clarified conceptually with team members. It thus creates common concepts and a common language within the team. The team can then act on its own interactions explicitly, i.e. take part to its own creation (Varela-), and influence it deliberately, adjusting what is necessary, integrating new capabilities, clarifying possibilities and interdictions and values, etc.

- Paramount was the use of consent for decision-making, particularly 3 levels consent [52], and the clear distinction of reflexion phases from decision phase, helped by the 'disagree and commit' principle [53].

In terms of model, the team acquired new capabilities, which changed its beliefs and values, that changed its identity, the way it looked at itself. This was a rapid development phase, nurtured.

It went from a team of capable doers (Erden 1 ) to a team of disciplined and motivated doers (Erden 2), then a building its autonomy (Erden 3) and realizing its responsibility, who then was able to co-design (and realize) a vision with its ecosystem in a distributed way (Erden 4). In other words, it went from a group of people being told from the outside what to do, to a team designing its future with and for its environment, i.e. switching from an external Locus of Control (LOC) ${ }^{28}$ to an internal LOC.

For the organization, this was the first successful experience of polycentric governance (SES7) . For the individual, this was also a transforming experience. For instance, one worker was strongly set against autonomy in the early stages, and expected clear orders from above, mostly focusing on technical matters and avoiding human matters because of their complexity; he later aspired to become a team leader, and also started a personal psychotherapy to gain clarity on himself.

\subsection{Managers Club}

A group of volunteer managers met at noon for a BBL ${ }^{29}$. It was a group of peers who learned from each other on the basis of simulated or real cases, a place for exchange and practice.

Typically this started with a five-minute meditation, to have a clear a break from the morning meetings, having a quick lunch together, and then an NVC practice session followed by organizational or vision case studies in which we applied systemic concepts.

Where appropriate, particular points of transmission were shared or improvised.

${ }^{28}$ Locus of control is the degree to which people believe that they have control over the outcome of events in their lives (internal), as opposed to external forces (beyond their influence) (external LOC) [54]

${ }^{29}$ BBL: Brown Bag Lunch. are workshops, seminars, and information sessions held at lunchtime. 
The cases shared were inspired by real cases that the managers had experienced during the week, making the experience grounded in reality.

These sessions combined conviviality that fostered connection, learning, systems thinking, training in peer for participation, learning to manage feedback loops and training in shared governance.

In addition to training people to have a systemic view; practices focused on distinguishing cases in the spiral dynamics, to understand the different behaviours and values, to distinguish them and to make them evolve, particularly at the level of participatory or directive decision-making, and the excesses into which one should not fall.

It was a safe training playground, a sandbox.

A common language had been created around SES, sociological levels, spiral dynamics and Dilts which formed a common vocabulary to talk about the system.

The NVC and meditation allowed them a level of detachment and self-reflection and allowed them individually to support and sustain themselves through difficult times - which happened when the environment was changing faster than we would like and we couldn't keep up with it, or when faced with particularly complex situations.

This setup therefore had the essential SES ingredients. (Tables 10-11). In addition, in terms of skills, there were intra-personal, inter-personal, conceptual, team management and strategic skills. In parallel to these weekly meetings, the managers had paired up to offer each other empathic listening and case discussions, as a form of mutual mentoring, reserving one hour per week on a recurring basis.

Table 10. Examples of coverage of techniques by SES criteria.

\begin{tabular}{cc}
\hline SES / S.Level & Intra-Personal \\
\hline $\begin{array}{c}\text { Diversity-redundancy } \\
\text { Connectivity } \\
\text { Slow }\end{array}$ & NVC \\
variables - feedback & Retrospectives, \\
CAS thinking & Stacey, \\
Learning & Cynefin... \\
Participation & Peer sharing \\
Polycentric & Structure \\
governance & Circles and \\
\hline
\end{tabular}

Table 11. Examples of coverage of techniques by Sociological Levels.

\begin{tabular}{cc}
\hline SES / S.Level & Intra-Personal \\
\hline Intra-Personal & Meditation \\
Inter-Personal & NVC \\
Groups & Liberating \\
& Structures \\
Group of groups & Sociocracy \\
Division & Dilts \\
Strategy & Visionning \\
& Wardley \\
\hline
\end{tabular}




\subsection{NVC Practice Groups, Meditations}

In addition to the managerial sessions described above, some people have expressed an interest in doing more meditation or deepening the practice of NVC.

For meditation it was 'organized' in a spontaneous way. When someone wanted to take a break, instead of a cigarette break or a coffee machine break, he would go for a meditation break in a small dedicated meeting room, after having posted a message on an instant messenger channel. People would come and leave freely, according to their wishes. This felt good and people discussed the experience very naturally afterwards. The practice became regular before the restart at 2 p.m.

There was no mystical aspect involved, just silent meditation (at the beginning was commented on the aspect of a detachment from the thoughts of the mind), introduced through the neuroscience angle. It was mainly considered a practice of relaxation of the frontal cortex overloaded by cerebral activity and stress, to help re-center oneself.

A circle of NVC was also created, but in a more structured way. A weekly meeting was set between noon and 2 p.m. Typically, a quick introduction was made, followed by 10-15 minutes of practice in simple cases, then more complex real cases, and sometimes a mini-course to deepen the concepts of NVC. Examples were taken from the daily life, typically conflict management or complex ambiguous situations. Among managers, it was seen that this allowed a detachment from beliefs and an ability to take a step back and better integrate their emotions, and a way to introduce emotions and needs into business language.

A practice derived from this was the evening peer coaching, i.e. before leaving, 2 peers would give each other 10 minutes of empathic listening in order to let go of the day, gain clarity and be able to express oneself without filtering and without waiting for an answer. The two partners played symmetrically. One listening, the other offloading, then reverse.

Both could then pause before returning home and can also escape the dance of obsessive thoughts.

This did, of course, create a link between the managers and tie them closer together. They would later use this peer coaching within their respective teams and will encourage peer-to-peer.

Some people who wanted to go further were trained in the transmission of NVC, which made the system more resilient, and self-replicating (propagate).

It is clear that the resilience of the people practicing meditation and NVC in terms of community was much higher than that of their colleagues who were isolated and underwent the change of system.

For those who touched empathic listening and the functioning of support groups, this was a new, refreshing and profound discovery that few have had the experience of. These managers will then fully understand the need to offer to listen instead of just telling people what to do, and therefore the evolution towards non-directiveness will be greatly facilitated after this personal experience. This was very useful to face emergence.

Conversely, a manager who was particularly brilliant intellectually but who had chosen not to expose himself to NVC was perceived to be severely limited. He had a yellow (SD) potential, yet still managed in the orange (SD) as he was not able to integrate the green level because of a lack of integration of empathy and listening. Facing emergence, he became rigid in his directive postures.

It should also be noted that the closer we get to emergence, the more non-directive postures are necessary in the face of uncertainty and the unknown, and the more management of collective intelligence is required.

Those who were stuck in the directive postures of knowledge fled from the uncertainty of emergence, or even fought emergence to prevent any evolution. 
Those who had experienced facing uncertainty and emergence had integrated this as a cultural point. Therefore whoever sought to manipulate them because they themselves were afraid of changing were quickly identified because this cultural element was clear.

\section{Discussion}

We will discuss the diffusion mechanism, the transformation, and the classical approaches.

\subsection{The Diffusion Mechanism}

A diffusion mechanism should be set, nurtured and structured. The mechanism should be structured vertically (across panarchical layers i.e. sociological levels), and also horizontally (across all entities on one sociological level, from the seeds team to other teams for instance). We chose to create networks and structure them as communities, to build resilience. They will be the transformation 'engine'.

Let's take the example of a human being. If he is given the opportunity to develop new abilities, he will want put them into practice. Give him the extra opportunity and that's it.

When the new skills (D3) eventually open up new possibilities (D4) and new motivations (D4), this will change the way he looks at what he believes he is. (D5.) This is actually climbing up the Dilts ladder.

If, in addition, his attention is drawn to the deliberate intention to change his ecosystem (D6) and he feels welcome to openly discuss change and its means with his peers, this will naturally create a network that supports change.

Now, structure this network and you will have a vehicle for transformation.

Replicate this among systems. This is the mechanism of dissemination.

In concrete terms, this means creating a certain number of communities around various themes, they will train and practise, recruiting around them, some of the members being members of several communities and will do cross-fertilization ${ }^{30}$.

Then we need to make sure that all sociological levels are covered [55] [56] e.g. meditation for interpersonal, interpersonal with the NVC, liberating structure for the group, manager networks for the group of groups, and strategic visioning for those who want to exercise leadership. A distributed leader network is an excellent way to create cross-fertilization on those who have elements of vision (D6).

It is important to differentiate networks and communities. Like Mintzberg said, 'Networks connect; communities care' [57]. Because networks without a recognized structure cannot co-operate (decide, co-ordinate) [58].

These communities are not a counter power to the existing executive chain of command.

They also provide a safe space where the paradox that results from the cohabitation of several cultures can be dissolved. [59] [60]

In summary:

- Initiate seeds, to prove the feasibility, the desirability, and the viability.

- Encourage local networks

- Structure them into communities

${ }^{30}$ This is an application of social constructivism. 
- Cross link them

- Clarify that a network/community is not a competitor to the execution structure, and dissolve paradoxes emerging

Here are some communities of practice we created, the technique shared, and the related sociological level reached:

- Liberating Structures (Team: Structure interaction),

- NVC (Interpersonal, Interpersonal),

- Meditation (Intrapersonal)

- Decision by consent (facing complexity, ambiguity, uncertainty) (Team)

- Vision building (strategy, using Dilts fractal 'lasagna' [51])

\subsection{Is this really a transformation?}

From what was described, an important question arises: is it really a transformation (L3)? An innovation (L2)? An improvement (L1)?

We don't have a simple answer:

- The three levels of change will coexist,

- Moreover, the perception will change according to the sociological levels

- It also depends on whether it is perceived from outside the system, or inside

Therefore, there may be confusion about the levels.

Let's take an example. Previously we explained that the seed team (see 3.2) created a vision that was validated with high management every 6 months and then carried it out to its execution autonomously.

This vision creation from the bottom up:

1. Is a form of improvement (L1) for the strategic level.

2. But it is an innovation (L2) for the teams

3. and it is a transformation (L3) for the individuals who have to do this

Indeed:

1. For the strategy level (Board of Directors), it is a simple improvement since their goal was already to draft vision. They just need to integrate it in a more global vision and to reconcile the pieces.

2. For the team, it is an innovation that, in a simple agile model, must be able to be autonomous in execution. Here the team must do something that they have never done before, but that they have seen done. It supposes the ability to interact (internally and externally) and to visualize and express clarity and to interact with the community.

3. The individual (or individuals) in the team who create this vision, has to become a 'visionary', whereas in the previous model he or she was an implementer. This means that he or she has to allows him or herself to think for him or herself (D4), to express his or her ideas clearly (D3) and to validate them with colleagues (D3) (in the team and in the community) ${ }^{31}$.

31 at the level of the individual strategic manager it is a transformation also, because he has to be able to listen and let go, instead of "telling". 
It is not only a series of competences (D3) to develop (interaction techniques, clarity) but also beliefs and values (D4) to change about one's role, one's authorizations, it is a profound change in the vision of one's role (D5) (L3)

Hence, a transformation at the individual level may be perceived as just an improvement at a strategic level.

Besides, there may be an internal-external confusion. Consider the individual trying to draft a vision on a visual board:

- Externally it may look like just an acquisition of technical skills (D3).

- While internally he must be able to think for himself (D4), allow himself to think differently than his boss (D4/D5) (LOC), a move from a paradigm of submission to a paradigm of partnership (D6) [61][62][63]

And therefore, what for an individual what is externally appearing as an improvement or innovation is in fact a transformation at the internal level.

If the system does not distinguish precisely the three levels of change, there will be confusion, both about the cognitive efforts involved - which are an order of magnitude higher at each level and about the time and efforts involved before expecting results.

\subsection{Transformation at Individual Level}

Netflix had a transformation at the organizational level, but at the individual and group level it was not. This was only the creation of a new activity, with new people, new ambition, an entrepreneur adventure.

As it expanded, it replaced the sources of income from the previous activity, which was declining (ecocycle: Release)

As we can see, there was no transformation at the level of individuals, as no worker from the warehouse was turned into an IT specialist. There was acquisition of new individuals with new capacities for the new activity, which is a classical entrepreneurial development: a start-up has an idea, then solves the related technical problems and manages to find a market. It is a great success but it is classic in its HR implementation (even if it is not common). Let us say it is a company that has been able to diversify, timely.

At the company level, this an L2 transformation, but at people level, just normal growth and adapt (L0-L1), no development and transformation.

In an agile transformation, we don't recreate a parallel activity, we ask the same people to do another type of job (D3-D4), or even to do it differently (D2) and with a different mindset (D4-D5).

It's not just an entrepreneurial or organizational challenge, it's also a challenge that requires an evolution in the understanding of the human psyche and sociology.

Certainly, some doers will acquire new skills (D3), or doers with these skills can be acquired directly on the market. On the other hand, the line manager, mid manager (and later strategic manager) will undergo a transformation of their job (D4-D5) and probably of their social identity. (D5) [64] 
They have to move from being planners and microcontrollers in a purely directive fashion, to being 'gardeners', non-directive coaches and trainers. That means not only acquiring new skills, but also a new mindset, and accepting to let go for some of their power and influence.

For most managers, this is a long way to go, and troubled waters ahead.

These D4-D5 transformations are internal, hence not so visible at first. It will cause uncomfortable and unstable, uncertain stages (Graves beta and gamma states ${ }^{32}$ ), and in our experience, most prefer to flee from it, rather than go through it. Giving support, like in support circles, definitely helps transition (Graves C6 criteria).

However this transformation of the chain of command is key to a successful transformation at group level; otherwise there will be no 'change of regime's3, and the structure will reform on the same basis.

\subsection{Other aspects}

There are too many aspects worth mentioning, documenting and researching, to fit within a single article. A brief list is included below:

Resilience: it is important to note that the transformation demonstrated its resilience in the face of the departure of the lead coach, a change of C-level management, a one-year power vacuum, and a change of local management. The transformation continued to operate, self-sustained.

Appetite for change: not everyone has the same appetence to change [65]; hence several value systems will coexist (social, cultures). This increases confusion between uncertainties and risk management.

Paradoxes and Multicultural Aspect: a system may face apparently contradictory constraints or orders, from different sources or layers. It may lead him in a 'frozen' state [60]. The key distinction was to frame the distinction between problem resolution and paradox dissolution. [59] [66]

As the systems grow, several cultures cohabit, several systems of beliefs (D4) that may confront. The key is to see it, explain it and permit it explicitly, from the top. Which is a contradiction to the belief 'one law for all' 34 that most may have in mind.

Why touch the intrapersonnel level when we are in the 'professional' area? The change that will be experienced by the individual within himself will be transposed into his professional role, bring him to congruence, and give him the confidence to apprehend the complexity of situations in the group or organizational level. To put it another way, no action without clarity, and at levels 2 and 3, clarity is (also) to be developed within oneself. Management cannot just order teams: 'transform yourselves', and hope for a result.

L2 change requires reflexivity: to see one's thoughts, one's beliefs. Otherwise you are condemned to act on the impulses of your thoughts, without any control, and consume the thoughts and beliefs of others. Acquiring reflexivity requires accompaniment, because it is not something natural, yet it is the difference between erudition and wisdom. The first is consumed, the second is the fruit of experience and hindsight, of letting go (or not). For the organization to be able to take

\footnotetext{
32 see 2.5.5, Mindset and Spiral Dynamics

${ }^{33}$ See 2.5.6 Ecocycle and Panarchy

${ }^{34}$ SD: Blue
} 
control of its destiny, of its identity, the individuals who make it up must develop this capacity. Especially and above all the managers who have formed the vision and who relay it. The lack of reflexivity condemns us to 'more of the same' (L0-L1).

This is why an organizational transformation will also be a personal transformation, and this is also why it may stall, because not everyone is ready or willing to transform themselves.

\subsection{Contrasting with the classical approaches}

We discuss why the classical approach mainly fails. We consider two common approaches found in the market ${ }^{35}$ and contrast them with the CAS approach:

-Case 1: the most classic case, where a transformation in the broadest sense is decided by the CEO and managed by an external consultancy.

-Case 2: one or more agile coaches are missioned to transforming an IT department.

Case 1: The CEO asks a famous consultancy firm to help transform the company. He gives general indications in the direction to go and sometimes include his top management, then request for proposals to the consultancy. This requirement leads to some generic ideas (the 'vision') and a Target Operating Model (TOM), the blueprint for the future organization. A plan is drawn up to go from the current situation to the target situation by the consultancy. A series of seminars are scheduled in the mid management to inform them or possibly try some participative mode to decline this vision in various action plans. Sometime the TOM it is combined with a product or process reorganization.

It comes out at least with a reorganization. Mid management is confused, feels threatened by uncertainty, and is generally in a very defensive mode, either openly or in a passive-aggressive way. There is no intervention directly at the team's level or the individual level. It is the mid management that is supposed to participate in implementing the transformation down to the operational level.

As the mindset (D4) are not affected, there is no evolution inside the strategic layer of the group, nor at mid management level.

The teams are not targeted by consultancy, and at the individual level, the operational managers tend to resist to what they perceive as an external inference.

This kind of approach could have achieved results in an industrial world where it was a question of restructuring an activity centred around production \& assembly line of machines, where people were just there to 'serve' the machine.

It has little effect in an IT world, where work is mainly an intellectual creation that requires trust, working in uncertainty, emergence.

\section{Review of C1:}

35 The main author has worked in such large consultancy, and involved in several of situations like Case 1 and 2 . the case may look caricatural, but those are the common case in the field. 
The changes are designed and directed from the outside and applied to the mid management layer ; those are afraid and, moreover, pressure from the outside leads them to be defensive. (closed mindset)

There is no work on the mindset, it is just a work of domination and pressure [67]. Not only is the mindset not affected, but also these close $(\mathrm{c} 0)$.

There are no mechanisms of diffusion, as the intended mechanism, mid-management, doesn't understand the changes and has no willingness to propagate them.

It focuses on growth and productivity (quantitative), it has no focus on development (qualitative).

Outcomes:

- The mid management does not change its mindset (and get closed on top)

- No impact on teams, individuals levels

- Finally, there is no evolution towards autonomy and the ability to develop.

More fundamentally, by considering the organization as a mechanical 'thing', it is not expected it will react, whereas being a cas, there will be reactions: homeostasis to try and preserve the current equilibrium, and defend itself from what is perceived as an external aggression.

This appears as a surprise and is considered as 'resistance to change'. Resistants are systematically eliminated or coerced into submission. In the end only the passive ones and the sycophant remains, and evolutive mechanism is suppressed.

This is generating the very maturity trap the top-level executives wanted to avoid in the first place. ${ }^{36}$

Case 2: The decision to implement 'agile' was decided by the head of IT, to accelerate software delivery, which is too slow. He expects significant results within one year.

Several agile coaches are recruited and deployed to 'transform' teams. They start a series of training sessions and show the teams how to use agile practices (D2) and tools (D1) to deliver (L1).

The principles are covered in two hours, from practices, training last one or two days.

In the field, coaches follow up and repeat the practice. They start some continuous improvement (L1) practices as well. If all goes well, 12 months later, the teams are compliant with the agile doctrine.

A slight acceleration in delivery is noted, as KPI shows. On the other hand, it is also noted that the business and the management systems have not switched to an agile mode, and there is tension between the doctrines. Long dogmatic discussions take place.

Business does not show an appetite for an agile transformation, and continue in its world as usual. They have no time to spend on this anyway.

As the tensions repeats with business, the results take too long to come. Some other solutions are investigated.

But the gap is growing. Those who see the interest of agile end up going elsewhere because the rest of the organization doesn't change fast enough for them.

There is no work on the mindset (D4-D5) of the chain of command or the business. small evolution (L1) take place among teams that practise agile

${ }^{36}$ The refusal of change, and sticking to existing structures. See Ecocyle in 2.5.6 or the reference card [28] 


\section{Review of C2:}

Only the layers D1-D2-D3 are touched while D4-D5 are not touched (the mindset, the identity.). No intra-team evolution, no regime change.

The upper sociological layer, the managers, continues to intervene and to give orders (then preventing autonomisation) and do not give the appropriate level of support (C6).

As the lower psychological layer, the intra-personal is not developed, individuals do not know how to face the paradoxical injunction (double blind) and go freeze (C2).

There is a surface improvement on the behavioural part (the process), but there is no change of mindset towards autonomy.

It's a faster caterpillar and not a butterfly.

Table 12. comparing transformation as CAS versus Top Down industrial vs Bottom up agile doctrine.

\begin{tabular}{|c|c|c|c|}
\hline Criterias & Transfo as CAS & Case 1 (Top Down) & $\begin{array}{l}\text { Case } 2 \text { (Agile } \\
\text { Doctrine) }\end{array}$ \\
\hline $\begin{array}{l}\text { View point on } \\
\text { organizations }\end{array}$ & CAS & $\begin{array}{c}\text { A thing, Mechanical, } \\
\text { Predictive }\end{array}$ & $\begin{array}{c}\text { Assembly of } \\
\text { individual and } \\
\text { teams }\end{array}$ \\
\hline Core Strategy & $\begin{array}{c}\text { Develop CAS } \\
\text { adaptability }\end{array}$ & $\begin{array}{l}\text { Define TOM and } \\
\text { resolve obstacle }\end{array}$ & $\begin{array}{l}\text { Apply Agile } \\
\text { doctrine }\end{array}$ \\
\hline Main target & $\begin{array}{l}\text { Regime change in all } \\
\text { Soc. Levels }\end{array}$ & $\begin{array}{c}\text { Org Chart and } \\
\text { Process } \\
\text { Quantitative }\end{array}$ & $\begin{array}{c}\text { Team's } \\
\text { Practices } \\
\text { Qualitative }\end{array}$ \\
\hline $\begin{array}{c}\text { Sociological levels } \\
\text { covered }\end{array}$ & All & $\begin{array}{l}\text { Strategy and } \\
\text { Managers } \\
\text { (Individuals) }\end{array}$ & Teams \\
\hline Dilts Level & D1-D6 & $\begin{array}{l}\text { D5 (objectives) D3 } \\
\text { (capabilities) }\end{array}$ & D2 Practices \\
\hline Level of Change & L0-L3 & L0-L1 & L0-L1 \\
\hline Aim for & $\begin{array}{l}\text { Development \& } \\
\text { Regime Change }\end{array}$ & Growth & $\begin{array}{c}\text { Speed and } \\
\text { adaptability of } \\
\text { production }\end{array}$ \\
\hline $\begin{array}{l}\text { Differentiate Growth } \\
\text { \& Development }\end{array}$ & Yes & No & No \\
\hline $\begin{array}{l}\text { Differentiate } \\
\text { Quantitative \& } \\
\text { Qualitative }\end{array}$ & Yes/Aim for Dev. & No & $\begin{array}{l}\text { No. Try and } \\
\text { quantify } \\
\text { Qualitative }\end{array}$ \\
\hline Vector of Diffusion & $\begin{array}{l}\text { Structured } \\
\text { Community }\end{array}$ & $\begin{array}{c}\text { Top Down 'Change } \\
\text { Agent' }\end{array}$ & Network \\
\hline $\begin{array}{c}\text { Differentiate } \\
\text { Antagonism - Paradox } \\
\text { vs Problem }\end{array}$ & Yes & No & No \\
\hline
\end{tabular}

\section{Conclusions}


The main take away is that for an organization to transform, its subsystems should transform too, and synergistically. Otherwise there will be no 'regime change', the system will re-form around the same principles.

For these, all layers should develop in order to new properties to emerge. Not only the visible layers (capabilities, behaviours and practices, tools-D3-D2-D1) but also the 'internal ones', the mindset: belief/values (D4)/identities (D5) (interactions between individuals, between teams, vision co-emergence).

A seed should be planted at every level to demonstrate the feasibility. These internal properties should be provided with language elements and evaluation ladders, so conversations can occur at every level, and diffuse through the organization. This diffusion should be structured to be resilient. Paradoxes from the cohabitation of several cultures should be addressed. The first elements to transform will be internal (mindsets) and only then can external elements adjust and propagate to higher levels (D6). This is slow ${ }^{37}$ but ineluctable.

Considering Organization as self-aware CAS is paramount, as the common conception current (industrial: mechanistic and predictive) results in bringing the systems in a frozen or defensive mode. It results in a strategy of bottom-up development ${ }^{38}$, smaller element developing faster,

Supplementary Materials: The following are available online at www.mdpi.com/xxx/s1, Figure S1: titles, Table S1: titles, video S1: title.

Author Contributions: For 'Conceptualization, L.T.; Methodology, L.T.; Validation, P.M. .; Investigation, L.T., C.R., M.T. D.M, S.B, D.P..; Resources, C.R..; Writing-Original Draft Preparation, L.T..; Writing-Review \& Editing, L.T., C.R., M.T. D.M, S.B, P.M., D.P.; Project Administration, C.R., ; Funding Acquisition, C.R..

Funding:: This research received no external funding

Acknowledgments: In this section you can acknowledge any support given which is not covered by the author contribution or funding sections. This may include administrative and technical support, or donations in kind (e.g. materials used for experiments).

Conflicts of Interest: “The authors declare no conflict of interest."

\section{Appendix A}

The figure A1 gives some details of what this x means in Table 7. This is simplified for skills only, on 3 Sociological Levels. Some structures or policies were also present, but too specific to this companies to be worth detailing in such a small article.

37 Slower than a transformation pushed from the outside, but these one fails, 7/10 bringing nothing, or at best a reorganization. (L1)

38 Supported by the top, but not managed by the top, or externally managed. 


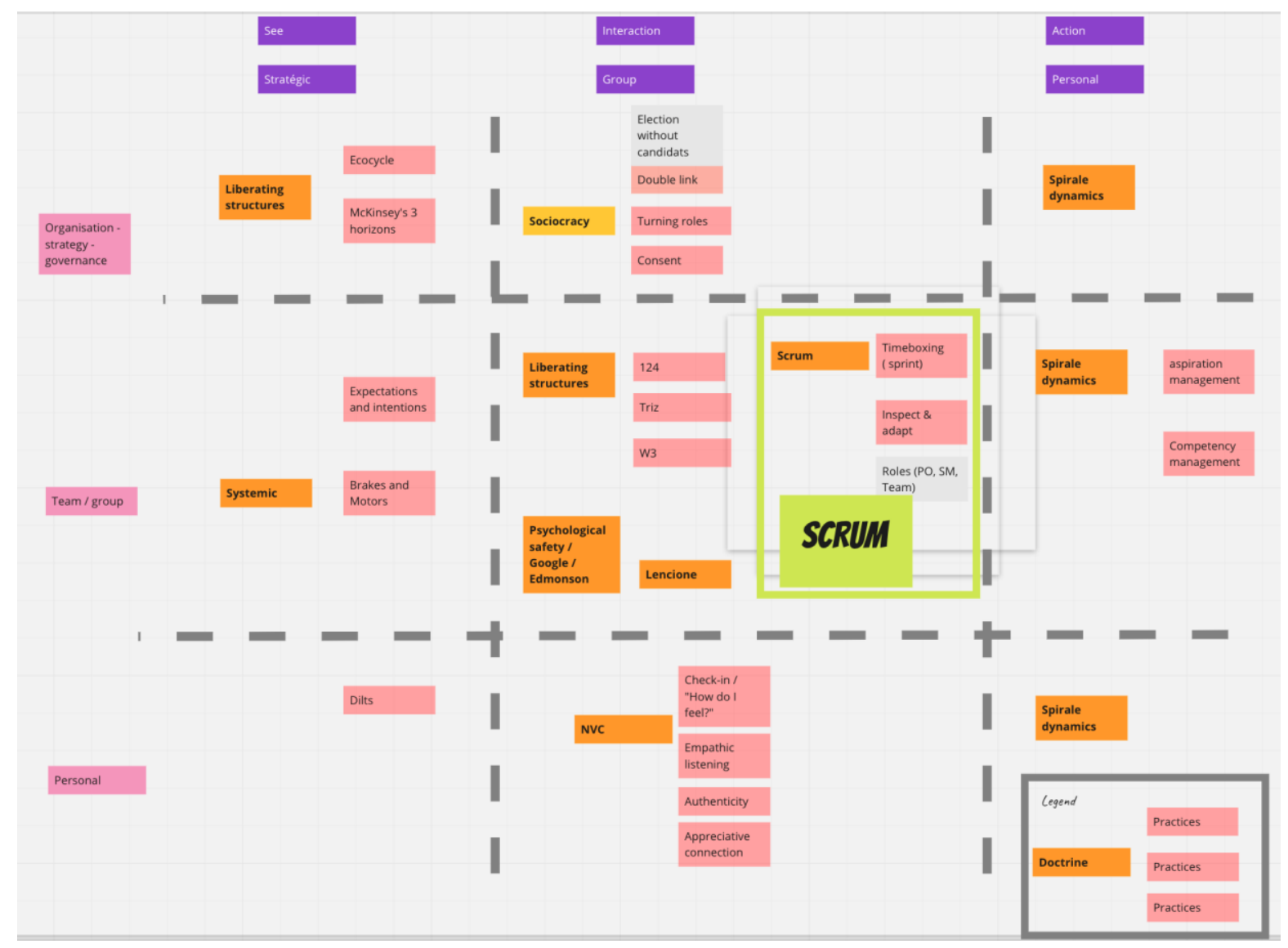

Figure A1. This shows which skills is deployed and impact which level. Vertical is sociological level, Horizontal is the differentiation See-Interact-Action i.e. Think-Decide-Action

\section{References}

1. Why do most transformations fail? A conversation with Harry Robinson | McKinsey Available online:

https://www.mckinsey.com/business-functions/transformation/our-insights/why-do-mo st-transformations-fail-a-conversation-with-harry-robinson (accessed on Oct 25, 2020).

2. Lucas, H.C.; Goh, J.M. Disruptive technology: How Kodak missed the digital photography revolution. J. Strateg. Inf. Syst. 2009, 18, 46-55, doi:10.1016/j.jsis.2009.01.002.

3. Doz, Y. The strategic decisions that caused Nokia's failure. Insead Website Novemb. 2017, 23.

4. McAvoy, J.; Butler, T. A Failure to Learn in a Software Development Team: The Unsuccessful Introduction of an Agile Method. In Information Systems Development: Challenges in Practice, Theory, and Education Volume 1; Wojtkowski, W., Wojtkowski, G., Lang, M., Conboy, K., Barry, C., Eds.; Springer US: Boston, MA, 2009; pp. 1-13 ISBN 978-0-387-68772-8. 
5. Muriel, O.; Sophie, R.; Astrid, R.; Frédérique, V. Digital Factory sont-elles un accélérateur de la transformation digitale des organisations ? 2020, 137.

6. Coch, L.; French, J.R.P. Overcoming Resistance to Change. Hum. Relat. 1948, 1, 512-532, doi:10.1177/001872674800100408.

7. Argyris, C. Overcoming Organizational Defenses: Facilitating Organizational Learning: International Edition; International Ed.; Pearson: Boston etc., 1990; ISBN 978-0-205-12882-2.

8. Ford, J.D.; Ford, L.W.; D'Amelio, A. Resistance to Change: The Rest of the Story. Acad. Manage. Rev. 2008, 33, 362-377, doi:10.5465/amr.2008.31193235.

9. An Agile Adoption and Transformation Survival Guide Available online: https://www.infoq.com/minibooks/agile-adoption-transformation (accessed on Jan 28, 2019).

10. Why many agile transformations fail | Accenture Insights Available online: https://www.accenture.com/nl-en/blogs/insights/why-many-agile-transformations-fail-a nd-how-yours-will-succeed (accessed on Oct 25, 2020).

11. Taesch, L. Self Directed Teams Available online: http://www.taesch.com/en/self-directed-teams (accessed on Oct 25, 2020).

12. Turner, J.R.; Baker, R. Just doing the do: A case study testing creativity and innovative processes as complex adaptive systems. New Horiz. Adult Educ. Hum. Resour. Dev. 2020, 32, 40-61, doi:10.1002/nha3.20283.

13. Bricage, P. Education for Sustainability: Lessons from Living Systems Governance. $J$. Syst. Sci. Inf. 2019, 7, 199-226, doi:10.21078/JSSI-2019-199-28.

14. Self-awareness. Wikipedia 2020.

15. Intentionality. Wikipedia 2020.

16. Pirotton, G. Des chiens ou des boules de billard?

17. Wikipedia Autopoï̀̀se. Wikipédia 2020.

18. Taesch, L. The Sociological levels - scale Available online: http://www.taesch.com/en/cognitive-en/complex-en/the-sociological-levels-scale (accessed on Oct 18, 2020).

19. Rousseau, D.; Billingham, J.; Calvo-Amodio, J. Systemic Semantics: A Systems Approach to Building Ontologies and Concept Maps. Systems 2018, 6, 32, doi:10.3390/systems6030032.

20. Dilts, R. Changing belief systems with NLP; Meta Publications Cupertino, CA, 1990; Vol. 990;.

21. Cheal, J. The Logical Levels of Organisations. Retrieved Sept. 2008, 3, 2011.

22. Lipmanowicz, H.; McCandless, K. The Surprising Power of Liberating Structures: Simple Rules to Unleash A Culture of Innovation; Liberating Structures Press: S.1., 2014; ISBN 978-0-615-97530-6.

23. Bateson, G. The Logical Categories of Learning and Communication. 28.

24. Tosey, P.; Langley, D.; Mathison, J. Bateson's levels of learning as a conceptual framework for workplace learning. 2010.

25. Argyris, C. On organizational learning; Blackwell business; Reprint.; Blackwell: Cambridge, Mass., 1996; ISBN 978-1-55786-663-9.

26. Dilts, R. From Coach to Awakener. 2003, 5. 
27. Beck, D.E.; Cowan, C.C. Spiral dynamics: Mastering values, leadership and change; John Wiley \& Sons, 2014; ISBN 1-118-77915-0.

28. Hurst, D.K.; Zimmerman, B.J. From Life Cycle to Ecocycle: A New Perspective on the Growth, Maturity, Destruction, and Renewal of Complex Systems. J. Manag. Inq. 1994, 3, 339-354, doi:10.1177/105649269434008.

29. Watzlawick, P. A review of the double bind theory. Fam. Process 1963, 2, 132-153.

30. Dawkins, R. The selfish gene; Oxford University Press: New York, 1976; ISBN 978-0-19-857519-1.

31. Graves, C.W. The Never Ending Quest: Dr. Clare W. Graves Explores Human Nature, a Treatise on an Emergent Cyclical Conception of Adult Behavioral Systems and Their Development; ECLET Publishing, 2005; ISBN 0-9724742-1-8.

32. Laloux, F. Reinventing organizations a guide to creating organizations inspired by the next stage of human consciousness; Nelson Parker: Brussels, 2014; ISBN 978-2-9601335-1-6.

33. Taesch, L. the 6 criteria for a level change in the spiral dynamics - Graves-Beck-Cowan Available online:

http://www.taesch.com/en/the-6-criteria-for-a-level-change-in-the-spiral-dynamics-grav es-beck-cowan (accessed on Oct 23, 2020).

34. Seidl, D. Luhmann's theory of autopoietic social systems. 2004, 28.

35. Holling, C.S. Resilience and stability of ecological systems. Annu. Rev. Ecol. Syst. 1973, $4,1-23$.

36. Taesch, L. Ecocycle. Serendipity 2018.

37. Gunderson, L.H. Panarchy: understanding transformations in human and natural systems; Island press, 2001; ISBN 1-59726-939-5.

38. Gotts, N.M. Resilience, panarchy, and world-systems analysis. Ecol. Soc. 2007, 12.

39. Allen, C.R.; Angeler, D.G.; Garmestani, A.S.; Gunderson, L.H.; Holling, C.S. Panarchy: Theory and Application. Ecosystems 2014, 17, 578-589, doi:10.1007/s10021-013-9744-2.

40. Pisano, G.P. Harvard Business Review. January 1, 2019,.

41. Doolittle, P.E. Constructivism and online education. 1999.

42. Ainsworth-Land, G.T. Grow or die: the unifying principle of transformation; Reissued ed., 1st ed.; Wiley: New York, 1986; ISBN 978-0-471-82971-3.

43. Gladwell, M. The Tipping Point: How Little Things Can Make a Big Difference; Back Bay Books: Boston, 2002; ISBN 978-0-316-34662-7.

44. taesch, L. Agile is post industrial. Why? (and why should you care ...) Available online: https://medium.com/@luc.taesch/agile-is-post-industrial-why-and-why-should-you-care -acef05765ba0 (accessed on Oct 25, 2020).

45. Taesch, L. SES Principles Available online: http://www.taesch.com/en/references-cards/ses-principles (accessed on Oct 25, 2020).

46. Biggs, R.; Schlüter, M.; Schoon, M.L. Principles for Building Resilience: Sustaining Ecosystem Services in Social-Ecological Systems; Cambridge University Press, 2015; ISBN 978-1-316-29992-0.

47. Erden, Z.; von Krogh, G.; Nonaka, I. The quality of group tacit knowledge. J. Strateg. Inf. Syst. 2008, 17, 4-18, doi:10.1016/j.jsis.2008.02.002. 
48. Taesch, L. Why team performs - the Aristotle project at Google Available online: http://www.taesch.com/en/agile-en/why-team-performs-the-aristotle-project-at-google (accessed on Oct 25, 2020).

49. Taesch, L.; Granja, D. d'Olievra A virtual obeya with Miro Available online: http://www.taesch.com/en/agile-en/a-virtual-obeya-with-miro (accessed on Oct 25, 2020).

50. Taesch, L. Structures Libérantes en 9 mn, Paris. Serendipity 2015.

51. Richard, P. Facilitation with Dilts Lasagna Available online: http://www.taesch.com/en/agile-en/facilitation-with-dilts-lasagna (accessed on Oct 24, 2020).

52. Taesch, L. Why 3 levels Consent? Available online: http://www.taesch.com/en/cognitive-en/complex-en/why-3-levels-consent (accessed on Oct 25, 2020).

53. Disagree and commit. Wikipedia 2020.

54. Locus of control. Wikipedia 2020.

55. Berkes, F.; Ross, H. Panarchy and community resilience: Sustainability science and policy implications. Environ. Sci. Policy 2016, 61, 185-193, doi:10.1016/j.envsci.2016.04.004.

56. Berkes, F. Rethinking Community-Based Conservation. Conserv. Biol. 2004, 18, 621-630, doi:10.1111/j.1523-1739.2004.00077.x.

57. Mintzberg, H. Harvard Business Review. October 5, 2015,

58. Delavallée, E. Transformation des organisations et transformation digitale : même combat! Quest. Manag. - Blog Eric Delavallée 2016.

59. Taesch, L. The probleme with paradoxes Available online: http://www.taesch.com/en/cognitive-en/changemanagement-en/le-probleme-des-parado xes (accessed on Oct 20, 2020).

60. Braathen, P. Paradox in organizations seen as social complex systems. Emergence Complex. Organ. 2016, 18, 1-14.

61. Montuori, A.; Eisler, R. The Partnership Organization. OD Pract. 2001, 33, 11-17.

62. Eisler, R.; garrick, lucy Leading the Shift from a Dominator to a Partnership Culture Available online:

https://thesystemsthinker.com/leading-the-shift-from-a-dominator-to-a-partnership-cult ure/ (accessed on May 11, 2020).

63. Taesch, L. Partnership systems versus domination Systems - Reading notes Available online:

http://www.taesch.com/cognitive/changemanagement/partnership-systems-versus-domi nation-systems-reading-notes (accessed on Oct 19, 2020).

64. taesch, luc the 7 canonical roles of a manager Available online: http://www.taesch.com/en/agile-en/7-canonical-roles-of-a-manager (accessed on Oct 24, 2020).

65. Taesch, L. Modeling reactions to change Available online: http://www.taesch.com/en/cognitive-en/changemanagement-en/modeling-reactions-to-c hange (accessed on Oct 20, 2020). 
66. Johnson, B. Polarity Management. Exec. Dev. 1993, 6, doi:10.1108/EUM0000000003846.

67. Romme, A.G.L. Domination, self-determination and circular organizing. Organ. Stud. 1999, 20, 801-832. 